\title{
USING ICT IN OCCUPATIONAL STRESS MANAGEMENT: THE VIEWS AND EXPERIENCES OF SRI LANKAN STRESS EXPERTS
}

\author{
Manoja Weerasekara ${ }^{1}$, Åsa Smedberg ${ }^{2}$ and Hélène Sandmark ${ }^{2}$ \\ ${ }^{1}$ School of computing, NSBM Green University Town, Pitipana, Homagama, Sri Lanka \\ ${ }^{2}$ The Department of Computer and Systems Sciences, Stockholm University, Kista, Sweden
}

\begin{abstract}
ICT supported health intervention is a phenomenon that has grown stronger in recent years. Although eHealth and mHealth care are an expanding area of ICT, the development has not been as significant as in other fields. Successful implementation of eHealth or e-mental health applications requires close collaboration between healthcare practitioners and system developers. Complex and multilayered factors determine healthcare practitioners' intention to use ICT in their practice. This study aims to understand the Sri Lankan stress experts' experience and perception of using ICT tools in their stress management practices. Eight stress experts in Sri Lanka were interviewed. Through thematic analysis, we identified three main themes and multiple subthemes. Results show that practitioners used only a limited set of internet resources in their stress management practices and preferred face-to-face consultations over distance/online communication. Overall, they appreciated the immediate benefits of ICT interventions while highlighting disutilities like the risk of misleading information and insufficient access to resources. Moreover, clients were regarded as empowered through increased access to new and more information. They were also encouraged to make their own decisions to a greater extent. However, there were also objections from practitioners who were reluctant to accept the client's ability to make decisions through self-education. This study can possibly provide a better understanding of the impact of ICT on stress management practices and knowledge to design and develop ICT tools for stress management.
\end{abstract}

\section{KEYWORDS}

eHealth, e-Mental Health, Health Intervention, Stress Management, Sri Lanka: Stress Expert

\section{INTRODUCTION}

Stress is a global phenomenon and a major healthcare challenge in the 21 st century. Almost everyone is exposed to a wide range of pressures in both personal and work life. Some individuals cope very well with these pressures. On the other hand, some individuals find it difficult to manage the situation, and that is when individuals fall into the "stress." Occupational stress is a branch of stress which is associated with one's work environment or job conditions. The imbalance of occupational "demands" and individual's "supply" will cause occupational stress (Mustafa et al., 2015); where high pressure, unrealistic goals and expectations within the occupation do not match with an employee's knowledge, skills and capacity. It is commonly believed that stress to a certain level is acceptable and considered positive, whereas the excessive amount of stress is deemed to be negative or potentially harmful to both physical and mental wellbeing (Lazarus, 1993). Nowadays, stress-related disorders are a significant public health matter in many countries and many organizations. The analysis of Global Employee Assistance Programs conducted across Asia, Europe, Africa, North America and South America, covering more than 100,000 employees, revealed a significant increase in stress reactions, anxiety and depression (Debnam, 2016).

Technology has become an integral part of people's everyday functioning, changing their lifestyle rapidly. People are willing to receive quality services effectively and efficiently through information and communication technology (ICT) enabled processes. Not only with the areas of business, education and transport, now there is a rising demand also for ICT supported healthcare delivery (Burney, 2010). Healthcare services, with eHealth and mHealth approaches, offer enormous potential for effective information exchange, reduction of costs and improvement of healthcare access. The term eHealth is referred 
as "health services and information delivered or enhanced through the Internet and related technologies" (Eysenbach, 2001, p. 2), whereas mobile health, or mHealth, is defined as the "use of mobile computing and communication technologies in health care and public health" (Free et al., 2010, p. 1). ICT supported health interventions provide avenues for a collaborative environment where patients and healthcare professionals connected virtually enable more personalised and customised services (Burney, 2010). Besides the ICT tools for collaboration between healthcare providers and patients, there are also online support groups allowing patients to gain a more autonomous role (Barrett, 2005). With online support groups, more patient participation and control can be achieved (Barak, Boniel-Nissim \& Suler, 2008; Barrett, 2005). Through the interaction with others, patients and other people with health concerns can learn about what resources to access, develop their ability to make personal decisions and to think critically (Barak et al., 2008). They get support to develop skills and abilities together with a more positive image of themselves leading to 'patient empowerment.'

ICT plays a significant role in identifying and overcoming stress-related disorders. It can help to improve the efficiency of interventions and make it possible to reach a broader audience regardless of time and geographical barriers (Cohen, Kessler \& Gordon, 1995). In the same way, ICT interventions allow the user to access information in a quick, easy and confidential manner (McKenna \& Bargh, 2000). Although eHealth and mHealth in mental healthcare are an expanding area, further development is needed (Schmidt \& Wykes, 2012). ICT enabled tools in mental health care are underused (Ennis, Rose, Callard, Denis, \& Wykes, 2011; Mclaren, 2005), and there is just little scientific evidence supporting investment in ICT-based psychosocial programs for resilience or prevention of posttraumatic stress symptoms, depression, or anxiety (Breslau \& Engel, 2016). This may be due to the unique challenges faced in developing and applying/using such ICT tools in the health sector, including financial capacity; infrastructure availability; knowledge and access to such resources; leadership and governance issues; and security, social and technical issues (Ariani, Koesoema \& Soegijoko, 2017).

Sri Lanka is a country with a national awareness on mental health concerns due to occupational stress. According to recent statistics at the Mental Health Unit of Sri Lanka's Health Ministry, one in five public sector employees suffers from stress, and this has become a real issue that needs to be addressed at the workplaces (ColomboPage, 2017). Sri Lanka is a small island lying southeast of India with a population of 21.02 million in 2019. It is the 58th most populous country in the world with multi-cultural and multi-ethnic identity. Sri Lanka is a developing country with an economically active population around 8.6 million in the first quarter 2017 of which 62.7\% are males and 37.3\% are females (Sri Lanka Labour Force Survey, 2017). Among them about $45 \%$ are engaged in the service sector, $28 \%$ in the industry sector and $27 \%$ in the agriculture sector. With the fast-paced industry and service environment, the competitive run to reach the next level, long working hours and lack of work-life balance have resulted in mental stress and mental disorders among workers (Rajgopal, 2010). Mental health care is provided through a combination of public, private and non-government services (De Silva, 2002). The psychiatric treatment service system is comprised of a network of hospitals at national, provincial and district levels. Primary care is managed by the district hospitals, the peripheral units and the rural hospitals, with referrals to higher institutions when necessary. Secondary care is provided by the base hospitals and, increasingly, by psychiatric inpatient units in district hospitals. Tertiary and sub-specialty inpatient psychiatric care is provided by the National Institute of Mental Health (World Health Organization, 2017). There is a small private psychiatric service sector. Psychiatrists working in the public sector may also carry out private practice outside the public working hours and provide approximately 50\% of outpatient care (De Silva, 2002). Mental healthcare is also provided by Ayurvedic and other indigenous practitioners (De Silva, 2002). Mental Health ATLAS 2017 Member State Profile of Sri Lanka recorded that there are only 1,480 mental healthcare professionals in both government and non-government sector, which gives $7.14 \%$ mental healthcare workers per 100,000 population. Considering the current shortage of mental healthcare human resources, there has been particular interest in introducing innovations to deal with the situation (Minas, Mendis, \& Hall, 2017).

Thus, this study specifically aims to understand the Sri Lankan stress experts' experience and perception of using ICT tools in their practice. The outcome of this research could feed-in as knowledge to design and development of ICT tools for stress management to yield optimum efficacy levels. 


\section{RESEARCH AIM AND OBJECTIVES}

Based on the introduction, this study aims to explore the Sri Lankan stress experts' experience and perception of the use of ICT for stress management interventions. This will provide a holistic understanding of perceived benefits and challenges of using ICT in their practice for stress management in the Sri Lankan context. The specific objectives of this research are: (1) to explore the use of ICT in stress management practices, (2) to identify the types of technologies that the stress experts prefer to use, and (3) to explore the challenges and benefits the stress experts perceive while using different technologies in their practice.

\section{LITERATURE REVIEW}

\subsection{Stress and Occupational Stress}

The term "stress" evolves after the 1920s, and it is a form of the Middle English "destresse," derived via Old French from the Latin word 'stringere', "to draw tight" (Keil, 2004). In a medical context stress is a physical, mental or emotional factor that causes bodily or mental tension. Stress can be external coming from the environment, psychological, or social situations. Stress can initiate the "fight or flight" response, a complex reaction of neurologic and endocrinologic systems. Occupational stress is associated with one's work environment or job conditions. Studies exploring the impact of work-related stress on organizational outcome have discovered forms of stress behavior affecting competitiveness, productivity and the public image of the organization. For example, besides the impact on workers' physical wellbeing, a poor psychosocial working environment contributing to work-related stress can result in increased absenteeism and presenteeism, as well as reduced commitment, motivation and satisfaction, along with a higher rate of staff turnover and intention to quit (Quick, 2013). At a broader level, stress-related disorders impact the economic and social environment of both individuals and organizations (Narváez, Tobar, \& López, 2014).

\subsection{ICT in Healthcare}

ICT acts as a catalyst agent of economic and social development and impacts across different sectors in society, including the healthcare sector. Use of ICT to deliver healthcare service has existed since 1999 (Della Mea, 2001) and has expanded rapidly over the years. ICT usage in healthcare mainly moves hand-in-hand with eHealth. eHealth technologies offer an enormous potential to advance healthcare communication, improve healthcare access and develop personalised medical service at a reduced cost (Ryu, 2010). For the current study, the definition of ICT provided by Afolabi and Abidoye (2011) seems much relevant. They describe ICT as "the usage of electronic devices such as computers, telephones, internet and satellite systems to store, retrieve and disseminate information in the form of data, text image and others" (Afolabi \& Abidoye, 2011, p. 2). This allows the researcher to focus on ICT in a holistic manner covering all the possible electronic, mobile and internet technologies use within the healthcare sector.

\subsection{ICT Supported Occupational Stress Interventions}

The use of ICT can help to improve the efficiency of interventions. It is possible to carry them out at a larger scale, regardless of time, place or group of people (Cohen, Kessler, \& Gordon, 1995), and the user can access information in a quick, easy and confidential manner (McKenna \& Bargh, 2000). Despite massive growth in the eHealth area, there is much to be studied to harness the electronic data for use in mental health services (Schmidt \& Wykes, 2012) showing that e-mental healthcare is an area of potential improvements in treatment delivery, shared care and decision making. For successful implementation of ICT in healthcare, especially in developing countries, there is a need to consider existing and potential challenges (Ariani et al., 2017). These challenges include funding needs, infrastructure, knowledge and research evidence, leadership and governance, security and interoperability, and sociocultural and technological environments (Ariani et al., 2017). Healthcare providers' active participation is a vital aspect of the ICT supported interventions. Their positive and active involvement will help to accelerate the adoption and deployment of such interventions 
within society. Therefore it is essential to recognize their views and experiences as they will have their own unique set of motivations, attitudes, knowledge, and skills, resulting in a plethora of unique challenges for engaging in such interventions (Ariani et al., 2017).

\section{METHODOLOGY}

This study is exploratory and qualitative and employs a phenomenological approach to understand the stress experts' experience and perception of using ICT in their stress management practices. As Penner et al. (2008) note: "a phenomenological analysis does not aim to explain or discover causes"...it is "to clarify the meanings of phenomena from lived experiences" (p. 93). Thus, this approach strengthens the objective of the study. A combined convenience and purposeful criterion sampling method was used to select respondents. Five of the interviewees were identified from the list of counsellors available at the psychologymatters.asia (www.psychologymatters.asia) website and through major governmental and non-governmental counselling service websites, one was added through a known contact and the last two were recommended by two of the other interviewees. The selected interviewees include counsellors from different governmental and non-governmental organizations (NGO). Two counsellors were affiliated with well-known government organizations, five counsellors were from leading non-governmental organizations and one was from a private organization. There were seven interviews done with the eight participants; one of the interviews was a group interview with two of the participants. The interviews were conducted in the period January 2019 to February 2019. This purposive selection of participants provides an opportunity to receive different views and ideas from different perspectives to enrich the understanding of an experience (Polkinghorne, 2005). Demographic data of the interviewees is detailed below in Table1.

Table 1. Respondent Demographic Data

\begin{tabular}{|l|l|l|l|l|l|}
\hline No: & Gender & $\begin{array}{l}\text { Age } \\
\text { Range }\end{array}$ & Education Qualifications & Experience & Affiliation \\
\hline I01 & Female & $50-55$ & Bachelor of Medicine & $\begin{array}{l}\text { Less than 5 } \\
\text { years }\end{array}$ & $\begin{array}{l}\text { Government } \\
\text { Organization }\end{array}$ \\
\hline I02 & Female & $50-55$ & Not revealed & $\begin{array}{l}\text { More than } \\
10 \text { years }\end{array}$ & $\begin{array}{l}\text { Government } \\
\text { approved charity } \\
\text { Organization }\end{array}$ \\
\hline I03 & Female & $45-50$ & Postgraduate Diploma in Counselling & $\begin{array}{l}\text { More than } \\
20 \text { years }\end{array}$ & $\begin{array}{l}\text { Non } \\
\text { governmental } \\
\text { organization }\end{array}$ \\
\hline I04 & Male & $60-65$ & $\begin{array}{l}\text { Diploma in Public Health-Royal Society of Health- } \\
\text { England }\end{array}$ & $\begin{array}{l}\text { More than } \\
15 \text { years }\end{array}$ & $\begin{array}{l}\text { Non profit non } \\
\text { governmental } \\
\text { organization }\end{array}$ \\
\hline I05 & Male & $50-55$ & Postgraduate Diploam in Counselling & $\begin{array}{l}\text { More than } \\
15 \text { years }\end{array}$ & $\begin{array}{l}\text { Non profit non } \\
\text { governmental } \\
\text { organization }\end{array}$ \\
\hline I06 & Male & $50-55$ & Postgraduate Diploma in Counselling & $\begin{array}{l}\text { More than } \\
15 \text { years }\end{array}$ & $\begin{array}{l}\text { Private } \\
\text { organization }\end{array}$ \\
\hline I07 & Female & $50-55$ & Diploma in Psychology and Diploma in Counselling & $\begin{array}{l}\text { More than } \\
25 \text { years }\end{array}$ & $\begin{array}{l}\text { Non } \\
\text { governmental } \\
\text { organization }\end{array}$ \\
\hline I08 & Female & $30-35$ & Diploma in Counselling and Pshychotherapist & $\begin{array}{l}\text { Less than 5 } \\
\text { years }\end{array}$ & $\begin{array}{l}\text { Non } \\
\text { governmental } \\
\text { organization }\end{array}$ \\
\hline
\end{tabular}

Data were collected through semi-structured interviews, which allowed the researcher to focus on specific themes while adhering to the conversational style of interviewing (Polkinghorne, 2005). All interviews took place in face-to-face mode based on the respondent's availability and preference. The first author made sure that the interviews were conducted in settings where the participants felt comfortable and convenient. The interviews were conducted using English or in the participant's native language (Sinhala), and each interview took 20-30min. Interview questions focused on background data and current stress management practices, 
how the interviewees used ICT in their stress management practices and other counselling activities and their experience and perception of ICT supported stress management interventions. All the interviews were audio recorded and transcribed to written text for analysis purpose. The verbatim transcribed interviews were analysed using inductive thematic analysis. Thematic analysis is the process of identifying, analysing, and reporting patterns from responses or data which allow the researcher to organise and describe the data in detail (Braun \& Clarke, 2006).

\section{ETHICAL CONSIDERATIONS}

This section of the article discusses the ethical considerations, the choices made to conduct an ethically sound investigation for the research approach. Before the data collection, each respondent received information about the study and how the collected data would be handled during and after the study, together with a request for their written consent to proceed. The interviews were recorded digitally, and each recorded data identified through a serial number guaranteed the anonymity of the respondents to anyone outside the study. The first author took ownership of the collection and responsibility for protecting it from unauthorized accesses. When interviews were done in other languages than English proper translation mechanism was followed involving professional translators to assure the accuracy and non-biases. Both translations and original transcriptions were checked by the first author, who read through the text and verified and reconciled it with the audio recording. The translations and transcribed text were verified with the respondents to assure that their original input is taken for the analysis purposes.

\section{RESULTS}

As a result of the coding of the participants' responses, three major themes emerged. In this section, the themes and their subthemes (see Table 2) are explained in detail. The descriptions are supported with direct quotations from the participants.

\subsection{Theme 01: Counsellors' Positive Experience of ICT Interventions in Stress Management Practices}

The theme "Counsellors' positive experience of ICT interventions in stress management practices" elaborates the various types of ICTs used in the stress counselling process and their purposes and advantages as perceived by the Sri Lankan counsellors. The theme consists of several subthemes.

\subsubsection{Provides Rich Sources of Resources}

The "Provides rich sources of resources" subtheme examines the types of ICT tools accessed and their usage during the stress counselling process. It was evident from the interviews that participants accessed a wide range of online materials to facilitate their stress counselling process. They used audio clips, video clips, guided imaginations, online assessment tools and other online tutorial for self-education purposes and to facilitate their stress management practices, for example simple relaxation activities. This enabled participants to use standard materials published from various professional organizations around the globe. They often mentioned that these materials improved their counselling process and that they were appreciated by their clients. This did not only apply to their stress related practices but also their other counselling approaches. Following extracts confirm this viewpoint:

I05: "We are also trying to find IT tools in our therapies. We online search for therapeutic music, we get therapeutic music from internet, we use such music for relaxation techniques, for laughing therapy we use video clips from the internet. There are many other therapies available online. First, we check whether they are appropriate to them."

I06: "So now annually and even daily basis all the diagnosis systems and other details for diseases and the disorders are changing so that now the previous year, whatever the things that we found as symptoms for a disorder may not be relevant, it's updated or changed with new information. Especially it is done by APA 
and other associations in the world. So, the information technology is a useful tool to refer to those associations' websites and their new methods to identify the new diagnosis methods."

Though there were objections from governmental counsellors, other participants believed that these online resources provided an opportunity for clients to seek information and educate themselves on their current situation.

I06: "Yes the point is now at this moment the world is very wide and that means many details and information available in the world. As a client, he can get to know about his disorder or the psychiatric problems or personal problems referring that information."

\subsubsection{Creates Reliable Communication Channel between Client and Counsellor}

The subtheme "Creates reliable communication channel between client and counsellor" consists of two parts. Firstly, ICT as a tool to reach clients. ICT tools allowed counsellors to access larger audience in an efficient manner. Participants mentioned that they used mobile and office telephone lines to reach their clients and answer client queries. They also mentioned that they used email to communicate with their clients. In some private organizations they used Skype to reach clients who were unable to visit the counsellor's place. Secondly, ICT to stay in touch with their clients. Participants referred to their use of ICT as a reliable mode of communication to increase their availability to clients. As stated by the participants, ICT devices allowed them to work from office and provide immediate advice to clients and to closely monitor their progression on assigned activities. ICT enabled communication channels also supported practitioners to reach clients who were reluctant to attend counselling sessions. These secure and confidential online approaches helped counsellors to build initial rapport and continue with further investigations. This is mentioned in following statements:

I04: "We have a hotline as online counselling. We can use the phone to start the initial conversation."

I03: "We give homework activities to our clients if we can make them online, we can see whether they're doing them and monitor their progress and advise them so it's convenient to client."

I06: "We need to keep contact with our clients more frequently at the time we need to pass messages. If we make this automated even when counsellor is busy this will continue the dialogue with the client. Then client will not get disappointed and the process also will continue. This is really good for clients with suicidal thoughts and also when clients are at critical and emotional situations."

\subsubsection{Provides Efficient Ways of Sharing Information}

This subtheme elaborates on how ICT can be used to share information among the public and clients. Participants also indicated that ICT allowed them to save time by eliminating travel to disseminate information as they could share their information through ICT systems such as websites, social media and e-mail. These ICT systems enabled wide distribution of information in much user-friendly manner. This supported them to publish materials and service information easily. It was also said that clients perceived this positively as they could receive information without physically attending the premises. The followings illustrate how they used ICT to share information:

I03: "On the one hand we are using our web site and it contains individual/group counselling programs. You can find a hotline so they can speak to us. There are many queries come from email asking for various information. We use Facebook to conduct campaign and publish information about our workshops."

I07: "We do have a web site and next we have a Facebook page, so we put all the required information there, we conduct email campaigns with an institute who does email campaign. We send emails to our counsellors' network and they pass the message to their friends and clients."

I02: "At the moment we are trying to develop our website and Facebook page to do all chat and increase the awareness."

\subsubsection{Enables Improvements to Existing Traditional Processes}

Last subtheme of theme 1 discusses how ICT can be used as a tool to enhance traditional stress management activities. Participants discussed how ICT allowed them to establish and practice more comprehensive activities within their traditional stress management activities. These ICT enabled forms allowed them to be more interactive with clients and efficiently uplift client's mental conditions. One participant, a counsellor from a government institute mentioned that ICT enabled them to restructure traditional practices adding technological exposure to create more avenues for clients to engage. As an example, one participant 
mentioned that instead of using traditional activities now they are practicing more interactive activities like karaoke, movie discussions, typing and online games with their clients. They have accessed YouTube, online music portals and multimedia projectors for these activities. The following illustrate their efforts and ideas on how to involve ICT during stress management practices:

I05: "On Sunday, we all watch films using multimedia projectors, after that we discuss the film. We use Karaoke app to play background music, and they sing along. They loved these activities. Likewise, we use a computer, a machine, to change people."

I06: "I believe that these computer-based techniques are more productive than our traditional approaches. We can develop customized programs for them, but there's only less focus or enthusiasm for such initiatives so if you can build up such programs, of course, we can use them at our centers."

Practitioners mentioned that they used ICT supported interventions for clients with severe mental illnesses and not only with the stress management activities. It is well explained with the following quote. (Note: Angoda is the location for National Institute of Mental Health).

I05: "If we look at Angoda mental hospital, still they ask these people to make envelopes, covers, etc. When a person comes with a good family background and social status, they tend to think "I was asked to do all these because I'm not mentally healthy" and they will come up with negative attitudes. They will reject these activities. But they prefer IT based techniques over the traditional approaches. It gives them self-pride."

Subsequently, theme 2 elucidates the counsellors' perceived negative experience of ICT interventions in stress management practices.

\subsection{Theme 02: Counsellors' Negative Experience of ICT Interventions in Stress Management Practices}

The theme "Counsellors' negative experience of ICT interventions in stress management practices" particularizes the counsellors' challenges encountered in the use of ICT and their adverse opinion concerning the ICT usage in stress counselling practices. This theme consists of four subthemes.

\subsubsection{Lack of Face-to-Face Communication}

This subtheme addresses the participants' negative viewpoints on using ICT for stress counselling practices. Participants appreciated the value of face-to-face communication in their counselling process. They explained that during the counselling process they meet with the client in a private and confidential setting to explore the problem client is having. They emphasized that this live conversation involved active listening, observing body language and facial expressions. They believed that other forms of communication settings could not allow this kind of rich communication. It is well evident through the following:

I03: "In counselling we should go one -to - one and I must see client's emotions, body language, change of facial expressions, whether they get angry while speaking, is he in sad mood or has a thought on commit suicide. This can be done only when we are seeing the client so we can hear what they hide from words. If we connect in other ways, we cannot get such hidden information."

I06: "When we do counselling, we need to keep eye contact and be emotional and interactive. So, if we ask them to use computer and look at web sites, that does not match with the counselling procedure. Counselling procedure is not like that. It is always a live conversation to sort out the problem [...]."

\subsubsection{Unavailability of Required Resources}

This subtheme examines the difficulties identified by the participants while searching for required content. They mentioned that sometimes available content is outdated, incorrect or biased. Since there is no universal standard followed by the content developers, counsellors believed that they need to be more careful when retrieving online content. They also mentioned that some important and more standardized contents are not freely accessible and required to be purchased. This is well evident through:

I06: "Actually sometimes when we refer or when access to some website content, they are not updated, that's one thing, the other thing is some content is not free, you need to pay."

I03: "Different people, organizations publish different materials but sometimes material that we need is not readily available. We need to verify content before we use." 


\subsubsection{Limited knowledge, resources and unfavorable experience}

The subtheme "Limited knowledge, resources and unfavorable experience" elucidates how counsellors discuss how the technical knowledge and experience impact on the ICT usage. The participants discussed that they have limited knowledge and training on ICT supported interventions. They also mentioned that even though they have required skillset sometimes there are no adequate ICT resources within their work premises. Participants further elaborated on their own negative personal experience of ICT in general. This is mentioned in these responses:

I05: "We have only eight computers, but we have 50 patients sometimes, it's a limitation."

I04: "Today we can see lots of people are on the train, but they are using their mobile phones and they don't want to talk to anyone. When they are crossing the road, they are using. I don't know what's going on with them. This is a problem. This has made many accidents as well. People are addicted to these mobile devices. You know, nowadays these devices computer and mobile phone is a problem for youngsters. Anyway, I think these computers and mobiles should be limited. Especially, it should not be a frequent thing for these stressed people. If they really want, they can access them once in a while."

\subsubsection{Risk of Misleading Information}

The last subtheme "Risk of misleading information" addresses how ambiguous material appears online could negatively affect the stress counselling process. The stress experts mentioned that this has twofold effect; firstly, it can mislead counsellors when they use it for self-education and secondly it can negatively impact on clients. Such false information and unsuitable content can rapidly spread on the Internet and reach larger audience and leave them at a vulnerable position. The participant also mentioned that when clients seek for information on their own, they can be misled or misguided while accessing inappropriate or irrelevant content. In such situations counsellors found it difficult to manage clients as they were reluctant to listen to the counsellors' advises. This is mentioned in following responses:

I03: "Some clients study themselves and they do not listen to us and they try to talk what they know. In that situation it is very difficult to move with them and bring them to the correct track. It can happen. Client doesn't know what exactly he needs to do. Sometimes information available online may be not suitable and relevant to that client, if he is using them it will make their situation more complex."

I04: "Different people publish different thoughts online, but we need to make sure the validity of the contents. With wrong information client might get wrong decisions."

I06: "If people share only good document or good tools or good pictures or ideas over Facebook/email/G+/twitter then social media is good. Negative part of the social media is it can harm people. Because social media is accessed by large number of people, within a minute you can pass wrong idea among the society. Yes. You know, uneducated people and those people who like to mislead other people also have access to these platforms. That is the problem. Now actually in our country most of the time we see how people misuse social media. So that's why I don't recommend always the social media for the counselling part or the development of mind of the people."

\subsection{Theme 03: The Perceived Challenges of Counselling Practice}

The final theme "The perceived challenges of counselling practice" elaborates problems identified in the counselling process in general and how ICT can be used to overcome such complications. This theme comprises of two subthemes: "Breaking the barrier" and "Fight or fly - a societal challenge".

\subsubsection{Breaking the Barrier}

This subtheme discusses clients' unwillingness to seek professional support and how this can be alleviated through ICT. The participants strongly believed that only a few percentages of people seek for professional support in stress conditions while a large group who need support is left unobserved. They further elaborated on that people are not willing to open up and share their thoughts with an outsider due to many reasons. This involves their busy lifestyle and experienced stigmatizing attitudes. Participants explained that ICT could be used to create positive social awareness about mental illnesses and motivate people to seek support. They further mentioned that social media (e.g. Facebook) allows people across communities to organize various online campaigns and local events to create awareness on mental health and support individuals. Following 
quotes show the barriers identified:

I02: "Even sometimes most of these people they don't care about stress. Stress management is not much addressed on the worker level context. It's mostly the management level problem."

I03: "First thing is we have to get people to talk and we have to say it's okay to talk. It's okay to talk. It's not a thing to be shy about, and talk about your issues, to open up, so that message has to go into our society."

I04: "Some people don't like to tell their issues. Just they come with a certain thing, but they may be having a different issue, but they say something different when they come to us."

\subsubsection{Fight or Fly - a Societal Challenge}

The last subtheme concerns the cultural aspect of dealing with stress. Participants mentioned that misbeliefs and strong social stigmatizing attitudes in the society are major barriers to mental health support seeking behavior. Living in a society with negative opinion on people with mental illness may further avoid individuals seeking for professional support. They further elaborated that this public stigma on mental illness can be reshaped with proper social awareness campaign.

I02: "Our society is not that open they want to bottle it up because of stigma around mental health issues. It is a vigorous thing because you have to break this barrier, the mental stigma around mental health issues. It's great still even among other rich people, knowledgeable, educated people, everyone."

I03: "We are getting emails mentioning their problem and they ask whether their conversations are confidential, and they ask whether they can take the counselling without physically attending to the premises. They are shy and afraid, and they want to meet counsellors, but they will not come."

Table 2. Summary of themes and subthemes

\begin{tabular}{|c|c|c|}
\hline $\begin{array}{c}\text { Participants' } \\
\text { views }\end{array}$ & Subthemes & Associated meaning \\
\hline \multicolumn{3}{|c|}{ Theme 01: Counsellors' positive experience of ICT interventions in stress management practices } \\
\hline \multirow{4}{*}{$\begin{array}{l}\text { ICT as a } \\
\text { positive tool } \\
\text { because it }\end{array}$} & Provides rich sources of resources & $\begin{array}{l}\text { Allow counsellors to access more standardized online resources to } \\
\text { support their counselling process }\end{array}$ \\
\hline & $\begin{array}{l}\text { Creates reliable communication } \\
\text { channel between client and } \\
\text { counsellor }\end{array}$ & $\begin{array}{l}\text { Allow counsellors to easily reach and stay in touch with larger } \\
\text { audience }\end{array}$ \\
\hline & $\begin{array}{l}\text { Provides efficient ways of sharing } \\
\text { information }\end{array}$ & $\begin{array}{l}\text { Facilitate a number of standardized and easy channels for sharing } \\
\text { of information }\end{array}$ \\
\hline & $\begin{array}{l}\text { Enables improvements to existing } \\
\text { traditional processes }\end{array}$ & $\begin{array}{l}\text { Provide alternatives to enhance the traditional counselling } \\
\text { approaches }\end{array}$ \\
\hline \multicolumn{3}{|c|}{ Theme 02: Counsellors' negative experience of ICT interventions in stress management practices } \\
\hline \multirow{4}{*}{$\begin{array}{l}\text { ICT as a } \\
\text { negative tool } \\
\text { due to }\end{array}$} & $\begin{array}{l}\text { Lack of face-to-face } \\
\text { communication }\end{array}$ & $\begin{array}{l}\text { How ICT interventions might diminish the traditional face-to-face } \\
\text { conversational approach }\end{array}$ \\
\hline & $\begin{array}{l}\text { Unavailability of required } \\
\text { resources }\end{array}$ & $\begin{array}{l}\text { Discusses on problems of unavailability of required materials } \\
\text { online }\end{array}$ \\
\hline & $\begin{array}{l}\text { Limited knowledge, resources and } \\
\text { unfavorable experience }\end{array}$ & $\begin{array}{l}\text { Elaborates on how counsellor's knowledge and experience impact } \\
\text { on ICT usage }\end{array}$ \\
\hline & Risk of misleading information & Discusses on false information and unsuitable content availability \\
\hline \multicolumn{3}{|c|}{ Theme 03: The perceived challenges of counselling practice } \\
\hline \multirow[t]{2}{*}{$\begin{array}{c}\text { ICT as a } \\
\text { possible tool }\end{array}$} & Breaking the barrier & $\begin{array}{l}\text { Discusses on clients' unwillingness to seek professional support } \\
\text { and how this can be alleviated through ICT }\end{array}$ \\
\hline & Fight or fly - a societal challenge & Elaborates on the cultural aspect of dealing with stress \\
\hline
\end{tabular}

\section{DISCUSSION}

The general objective of this study was to explore the Sri Lankan stress experts' views and experiences of ICT supported stress management interventions. The three main themes and ten subthemes extracted from the interviews provided valuable insights into the usage and role of ICT in stress counselling. The findings 
did not only highlight counsellors' negative and positive experiences of ICT usage but also pointed out the role that ICT plays to break the mental health stigma.

One key finding from this study was that the counsellors' overall positive experience of using ICT outweighed the negative ones. The interviews uncovered a variety of ICT tools used in the stress counselling practices. The counsellors mainly used websites and Facebook to disseminate information. They also used YouTube to play videos and audio during therapies. Further, counsellors elaborated that ICT supported interventions improved dissemination of health information, enabled remote consultation, facilitated collaboration and cooperation among clients, improved the efficiency of traditional stress management activities, supported more effective self-learning through access to information and facilitated public discourse and dialogue about mental health. These findings perfectly match with the results of a study carried out by Healthlink Worldwide (2007) focusing on the health sector of developing countries.

The study also revealed challenges and drawbacks of using ICT in stress management practices. The major constraint that the counsellors have identified is that ICT interventions could decrease the face-to-face communication. The most common way of arranging stress interventions can be described as confidential, individual, face-to-face counselling with a trained professional (Eisen, Allen, Bollash \& Pescatello, 2008). Sri Lankan stress experts also adhered to this model and highly valued the importance of having face-to face conversation to build rapport with the client. This is a crucial point to consider when developing ICT supported stress interventions. The system developers need to make sure that ICT tools support similar functionality and capture all elements of the conversation. Next, counsellors were constrained by the limited access to useful interventions and validity of the online content. Ward et al. (2008) also highlighted similar issues identified around the flexibility of the ICT systems and whether they were 'fit for purpose', along with the confidence and experience of the users. Such unfavorable experiences could have resulted in negative opinions on ICT supported interventions in their work life. Therefore, it is important to consider participants' characteristics and practices in the intervention design.

During the interviews different arguments emerged on client empowerment and about improving health literacy through self-education. Empowerment in health care generally refers to the process that allows an individual or a community to gain the knowledge, skills and attitude needed to make choices about their care (World Health Organization, 2017). Research studies also show that active and positive participation in online communities and social media allows people to learn about different worldviews and positive stress-relief strategies that can spread to local context. While there were objections from government attached counsellors in our study, others suggested that ICT could empower their clients by providing opportunity for the clients to educate themselves, improve their health literacy and to make healthcare decisions.

The stigma of mental illness is common and defines a process involving discrimination, stereotypes and prejudice (Rusch, Angermeyer, \& Corrigan, 2005). Mental health stigmatizing attitudes continue to be prominent in Sri Lankan as well. Persons experiencing mental health problems are subject to discriminatory practices, including decreased employment options (Consumer Action Network for Mental Health, 2015). Mental health stigma has been reported to affect health-seeking behaviors (Fernando, Pedersen \& Weerackody, 2010) and quality of treatment received (Fernando, Deane \& McLeod, 2010). As in the general population, health professionals also frequently have negative attitudes. A study showed that the majority of Sri Lankan doctors and medical students believed patients with mental illness are dangerous, unpredictable and difficult to communicate with, and that they perceive the world differently (Liyanage, Rowel, Hewawitharana, Silva \& Dissanayake, 2018).

Despite the lack of comprehensive research evidence to date, ICTs hold potential in addressing the challenges of mental health care (Breslau \& Engel, 2016). Similarly, the result of the study presented in this paper provides several promising insights for challenges identified in the area of stress interventions, and regarding mental health interventions in general, in the Sri Lankan context. Our study contributes to the area by exploring the Sri Lankan counsellors and stress practitioners' perceptions on ICT supported stress interventions. Thus, this study will lay an initiation for fruitful discussions on the role of ICT in stress management interventions. 


\section{CONCLUSION}

Over time, the research literature and experience with ICTs will grow, and consensus will form on which ICT applications are of greatest benefit to patients and clients who are in need of stress management. Thus, the results of this study could contribute to the already existing knowledge base, giving a better understanding of the possibilities and difficulties related to using eHealth solutions in clinical stress management practices in Sri Lanka. It also clarifies what technologies are more commonly utilized in mental health and highlight how ICT could help to better target mental health problems. The findings could also contribute to future design and development of ICT tools for stress management in Sri Lanka. It is also relevant to investigate clients' and employees' experiences and views on ICT supported stress management in future studies.

\section{REFERENCES}

Afolabi, A. F., \& Abidoye, J. A. (2011). The Integration of Information and Communication Technology in Library Operations Towards Effective Library Services. In Proceedings of the 1st International Technology, Education and Environment Conference (pp. 620-628).

Ariani, A., Koesoema, A. P., \& Soegijoko, S. (2017). Innovative Healthcare Applications of ICT for Developing Countries. https://doi.org/10.1007/978-3-319-55774-8

Barak, A., Boniel-Nissim, M., \& Suler, J. (2008). Fostering empowerment in online support groups. Computers in Human Behavior, 24(5), 1867-1883. https://doi.org/10.1016/j.chb.2008.02.004

Barrett, M. J. (2005). Patient Self-Management Tools: An Overview Patient Self-Management Tools: An Overview CALIFORNIA HEALTHCARE FOUNDATION, (June).

Braun, V., \& Clarke, V. (2006). Using thematic analysis in psychology. Qualitative Research in Psychology, 3(2), 77-101. https://doi.org/10.1191/1478088706qp063oa

Breslau, J., \& Engel, C. . (2016). Information and Communication Technologies in Behavioral Health A Literature Review with Recommendations for the Air Force. Rand Health Quarterly, 5. Retrieved from https://www.ncbi.nlm.nih.gov/pmc/articles/PMC5158232/\#!po=95.0000

Burney, S. M. A. (2010). Information and Communication Technology in Healthcare Management Systems: Prospects for Developing Countries. International Journal of Computer Applications, 4(2), 27-32.

Cohen, S., Kessler, R., \& Gordon, L. (1995). Strategies for measuring stress in studies of psychiatric and physical disorders. Measuring stress: A guide for health and social scientists. New York. Retrieved from http://www.psy.cmu.edu/ scohen/Cohen, S et al (1995).pdf

ColomboPage. (2017). ColomboPage News Desk, Sri Lanka. Retrieved May 3, 2019, from http://www.colombopage.com/archive_17B/Oct10_1507658756CH.php

De Silva, D. (2002). Psychiatric service delivery in an Asian country: the experience of Sri Lanka. International Review of Psychiatry, 14(1), 66-70. https://doi.org/10.1080/09540260120114096

Debnam, D. (2016). Huge Rise in Global Employee Depression, Stress, and Anxiety Since 2012. Retrieved from https://www.huffingtonpost.com/dean-debnam/huge-rise-in-global-employee_b_8923252.html

Della Mea, V. (2001). What is e-health (2). The death of telemedicine? Journal of Medical Internet Research, 3(2).

Ennis, L., Rose, D., Callard, F., Denis, M., \& Wykes, T. (2011). Rapid progress or lengthy process? electronic personal health records in mental health. BMC Psychiatry, p. 117. https://doi.org/10.1186/1471-244X-11-117

Eysenbach, G. (2001). What is e-health? Journal of Medical Internet Research, 3(2), E20-E20. https://doi.org/10.2196/jmir.3.2.e20

Fernando, S. M., Deane, F. P., \& McLeod, H. J. (2010). Sri Lankan doctors' and medical undergraduates' attitudes towards mental illness. Social Psychiatry and Psychiatric Epidemiology, 45(7), 733-739. https://doi.org/10.1007/s00127-009-0113-6

Fernando, S., Pedersen, D., \& Weerackody, C. (2010, July). Mental health in Sri Lanka. Lancet (London, England). England. https://doi.org/10.1016/S0140-6736(10)61072-0

Free, C., Phillips, G., Felix, L., Galli, L., Patel, V., \& Edwards, P. (2010). The effectiveness of M-health technologies for improving health and health services: a systematic review protocol. BMC Research Notes, 3(1), 250. https://doi.org/10.1186/1756-0500-3-250

Healthlink Worldwide. (2007). Improving Health, Connecting People: The Role of ICTs in the Health Sector of Developing Countries A Framework Paper. Retrieved from http://www.infodev.org/infodevfiles/resource/InfodevDocuments_84.pdf 
Keil, R. M. K. (2004). Coping and stress: a conceptual analysis. Journal of Advanced Nursing, 45(6), 659-665. https://doi.org/10.1046/j.1365-2648.2003.02955.x

Lazarus, R. S. (1993). From Psychological Stress to the Emotions " A History of Changing Outlooks. Annual Review of Psychology, 44, 1-21.

Liyanage, U., Rowel, W., Hewawitharana, U. H., Silva, V. De, \& Dissanayake, D. M. T. (2018). Stigma due to their work in mental health, among mental health professionals in Sri Lanka. Sri Lanka Journal of Psychiatry, 9(1), 4-8.

McKenna, K. Y. A., \& Bargh, J. A. (2000). The Implications of the Internet for Personality and Social Psychology. Personality and Social Psychology Review, 4(1), 57-75.

Mclaren, P. (2005). health care. Journal of the Royal Society of MedicinE, 98, 232-234. Retrieved from https://www.ncbi.nlm.nih.gov/pmc/articles/PMC1129049/pdf/00980232.pdf

Minas, H., Mendis, J., \& Hall, T. (2017). Mental Health System Development in Sri Lanka. https://doi.org/10.1007/9781-4899-7999-5

Mustafa, M., Illzam, E. M., Muniandy, R. K., Hashmi, M. I., Sharifa, A. M., \& Nang, M. K. (2015). Causes and Prevention of Occupational Stress. IOSR Journal of Dental and Medical Sciences, 14(November 2015), 98--104. https://doi.org/10.9790/0853-1411898104

Narváez, S., Tobar, Á. M., \& López, D. M. (2014). Systematic review of interventions supported by ICT for the prevention treatment of occupational stress. In Studies in Health Technology and Informatics (Vol. 200, pp. 71-80). https://doi.org/10.3233/978-1-61499-393-3-71

Penner, J. L., \& McClement, S. E. (2008). Using Phenomenology to Examine the Experiences of Family Caregivers of Patients with Advanced Head and Neck Cancer: Reflections of a Novice Researcher. International Journal of Qualitative Methods, 7(2), 92-101. https://doi.org/10.1177/160940690800700206

Polkinghorne, D. E. (2005). Language and meaning: Data collection in qualitative research. Journal of Counseling Psychology, 52(2), 137-145. https://doi.org/10.1037/0022-0167.52.2.137

Quick, J. C. (2013). Preventive stress management in organizations (2nd ed.). Washington, District of Columbia: American Psychological Association.

Rajgopal, T. (2010). Mental well-being at the workplace. Indian Journal of Occupational and Environmental Medicine, 14(3), 63-65. https://doi.org/10.4103/0019-5278.75691

Rusch, N., Angermeyer, M. C., \& Corrigan, P. W. (2005). Mental illness stigma: concepts, consequences, and initiatives to reduce stigma. European Psychiatry: The Journal of the Association of European Psychiatrists, 20(8), 529-539. https://doi.org/10.1016/j.eurpsy.2005.04.004

Ryu, S. (2010). History of Telemedicine: Evolution, Context, and Transformation. Healthcare Informatics Research, 16(1), 65-66. https://doi.org/10.4258/hir.2010.16.1.65

Schmidt, U., \& Wykes, T. (2012). E-mental health - a land of unlimited possibilities. Mental Health Journal, 21(4), 327-31. https://doi.org/10.3109/09638237.2012.705930

$\begin{array}{lllll}\text { Sri Lanka Labour } & \text { Force } & \text { Survey. } & \text { (2017). } & \text { Retrieved }\end{array}$ http://www.statistics.gov.lk/samplesurvey/LFS_Q1_Bulletin_WEB_2017_final.pdf

Ward, R., Stevens, C., Brentnall, P., \& Briddon, J. (2008). The attitudes of health care staff to information technology: a comprehensive review of the research literature. Health information and libraries journal (Vol. 25). England. https://doi.org/10.1111/j.1471-1842.2008.00777.x

World Health Organization. (2017). Mental Health ATLAS 2017 Member State Profile Sri Lanka. Retrieved from https://www.who.int/mental_health/evidence/atlas/profiles-2017/LKA.pdf?ua=1 